\title{
Sulcoplastia mandibular e enxerto epitelial
}

\author{
Joāo Batista Burzlaff* \\ Dalva Maria Pereira Padilha** \\ Edela Pirucelli*** \\ Taís Weber Furnaletto de Azambuja ${ }^{\star \star \star \star}$
}

\begin{abstract}
RESUMO
Os autores apresentam uma revisāo da literatura sobre sulcoplastia com enxerto epitelial e descrevem os procedimentos cirúrgicos utilizados na atualidade.

\section{SUMMARY}

The autors presents a literature review about sulcoplasty with skin graft and make a description of the surgical procedures applied in the present time.
\end{abstract}

\section{UNITERMOS}

Sulcoplastia, enxerto de pele, cirurgia pré-protética.

\section{Introdução}

A sulcoplastia com enxerto de pele é uma técnica cirúrgica que apresenta excelentes resultados em casos de atrofia de rebordo alveolar dos maxilares especialmente na mandíbula.

Ao contrário de outros procedimentos cirúrgicos que visam o aprofundamento do vestíbulo, tais como, o método de epitelização secundária e o enxerto livre de mucosa, a sulcoplastia com enxerto epitelial não apresenta o problema de recidiva no pós-operatório mesmo quando aplicada na mandíbula. Todas as demais técnicas de sulcoplastia tendem a faIhar quando aplicadas no maxilar inferior, devido a forte ação dos músculos faciais inferiores; particularmente a musculatura do mento. Somente a aplicaçăo de um enxerto de pele sobre o periósteo é capaz de frear a proliferação de tecido conjuntivo e o reassentamento dos músculos dissecados no trans-operatório. O sucesso obtido com a utilização das técnicas de enxerto de pele descritas por SCHUCHARDT (11), REHRMAN (9) e OBWEGESER (5), incentivaram a utilização da sulcoplastia com enxerto epidérmico no maxilar superior.
A sulcoplastia com enxerto epitelial é, em muitas situaçōes, o único meio de obter-se uma área chapeável e condiçōes para retenção de uma futura prótese total de uma grande parcela de pacientes edentados totais.

\section{Revisão da Literatura}

O uso de enxerto epidérmico na cavidade oral foi descrito inicialmente por TIERSCH em 1874, conforme relato de SCHWITZLER e EWALD (10) (1894), que foram os primeiros a utilizar o enxerto de TIERSCH na mucosa bucal.

Os primeiros enxertos de pele aplicados com o intuito de aprofundar o sulco bucal na mandíbula foram realizados por via extra-oral em 1916 (MOSCOWICKZ) (4) e 1917 (ESSER) (1).

Nestas técnicas, a partir de uma divulsão até próximo a mucosa oral, criava-se um leito para a inserção do enxerto de pele, que permanecia sepultado com um guia de cicatrização. Secundariamente, após um período inicial, a mucosa sobrejacente à pele era incisada proporcionando um novo sulco.

WEISER (16) em 1918 e PICKERILL (7) em 1919 aplicaram pela primeira vez o enxerto epidérmico com a utilização de guia cirúrgico e acesso intra-oral. GILLIES (2) e WALDROM (4) utilizaram a técnica descrita por PICHERILL e WEISER aplicando o enxerto de pele com guia cirúrgico na maxila.

PICHLER (6), em 1931, foi provavelmente o primeiro autor a descrever um grande número de casos tratados com sucesso pela técnica intra-oral de vestibuloplastia com enxerto de pele.

WASSMUND (5), em 1931, sugeriu o rebaixamento da inserção do músculo genioglosso e MATHIS (3), em 1951 o rebaixamento do músculo milohioídeo.

Várias técnicas cirúrgicas para aprofundamento dos sulcos vestibular e lingual da mandíbula e vestibular da maxila tem sido relatados desde 1916. Entretanto, os princípios da

* Professor Auxiliar da Disciplina de Cirurgia Bucomaxilofacial FO/UFRGS.

** Professora Assistente da Disciplina de Cirurgia Bucomaxilofacial FO/UFRGS. Mestre em Cirurgia.

*** Professora Adjunta da Disciplina de Cirurgia Bucomaxilofacial FO/UFRGS. Doutora em Cirurgia.

$\star \star \star \star$ Professora Assistente da Disciplina de Cirurgia Bucomaxilofacial FO/UFRGS. Mestre em Educaçāo. 
técnica intra-oral do enxerto e pele, foram pouco alterados até o surgimento da técnica de SCHUCHARDT (11), que sugeriu a sobreposição do enxerto de pele sobre uma superfície de periósteo. Para execuçāo desta foi desenvolvida uma técnica de sutura que unia o bordo da mucosa livre do lado lingual contra o periósteo no fundo do recém criado sulco.

A combinação da vestibuloplastia com enxerto de pele e simultâneo rebaixamento do assoalho da boca foi descrita por REHRMAN (9) em 1953 e OBWEGESER (5) em 1964. REHRMAN descreveu o uso de ligaduras sub-mandibulares para tracionar os bordos livres da mucosa e as margens da ferida. OBWEGESER combinou os procedimentos de WASSMUND (15) e MATHIS (3), atingindo o completo rebaixamento do assoalho da boca obtendo com esta associação de técnicas uma menor recidiva.

\section{Técnica Cirúrgica}

A técnica cirúrgica utilizada atualmente é uma associação da técnica de enxerto de pele descrita por SCHUHARDT (11) com o método de rebaixamento do assoalho da boca aperfeiçoado por OBWEGESER (5) a partir do método original de TRAUNER (14) (1952).

$O$ ato cirúrgico deve ser realizado em ambiente hospitalar com o paciente sob anestesia geral. Uma incisăo linear horizontal do lado do vestíbulo é realizada sobre o rebordo, atingindo de uma regiáo de primeiro molar a outra. A incisão deve ser realizada apenas através da mucosa de maneira a permitir a dissecção supraperióstea. 0 nervo mentoniano deve ser identificado e sua posição analisada. Se a emergência estiver localizada próxima a crista, esta deve ser transposta inferiormente através da criação cirúrgica de uma cripta óssea. A dissecção é aprofundada lateralmente em direçăo distal da regiāo correspondente ao primeiro molar. $\mathrm{Na}$ regiāo do mento, a dissecção não deve ser levada até o bordo inferior, evi- tando desta forma a tração exagerada dos tecidos moles da regiăo mentoniana no pós-operatório. Após a dissecção completa do vestíbulo, realiza-se a incisão lingual, também próxima a crista e paralela a incisão vestibular. 0 músculo Milhioideo em sua totalidade e a porção superior do genioglosso são dissecados. Realiza-se então o rebaixamento simultâneo do assoalho da boca. A fixação da mucosa marginal é feita pela técnica de sutura descrita por REHRMANN (9) que traciona o assoaIho da boca ao uni-lo com os tecidos moles do lado do vestíbulo, com os fios passando por baixo do corpo mandibular. A faixa de mucosa firme e normal resultante das incisões paralelas sobre a crista do rebordo alveolar, deverá permanecer para que a pressão exercida pela prótese total seja bem tolerada no pós-operatório tardio.

Uma vez preparado o leito receptor, procede-se a remoção do enxerto de pele. Uma faixa de pele de aproximadamente $15 \mathrm{~cm}$ de comprimento por $6 \mathrm{~cm}$ de largura é removida da zona doadora eleita no préoperatório (nádega ou coxa). 0 enxerto deve possuir aproximadamente $0,8 \mathrm{~mm}$ de espessura (8). É importante que este seja obtido de uma região que não possua pelos. Eventualmente apesar da pouca espessura, o enxerto poderá conter folículos pilosos, ocasionando o desenvolvimento de pelos no interior da cavidade oral no pós-operatório. A progressiva paraqueratização do tecido com a constante presença da saliva, desativa o folículo piloso. O sítio doador regenerará em aproximadamente 3 semanas.

Após a remoção do enxerto, com o auxílio de uma moldeira acrílica confeccionada no pré-operatório, é realizada uma moldagem com material termo-plástico. A moldagem é retirada da cavidade oral e sobre esta é colocado o enxerto com sua porção cruenta voltada para cima. Este conjunto deverá funcionar como veículo para manter o enxerto sobre leito receptor. Suturas circunmandibulares a fio metálico, estabilizam o conjunto. Após 14 a 21 dias, as suturas são retiradas e a contensāo removida. Depois de um período que varia de 3 a 6 semanas, o paciente deve ser encaminhado para confecção da prótese total.

\section{Conclusão}

A técnica de sulcoplastia com enxerto de pele é indicada para pacientes com atrofia óssea e que apresentem tecidos moles em condiçōes desfavoráveis para o uso de uma prótese total. Na mandíbula, entretanto, a técnica limita-se a pacientes portadores de altura do corpo mandibular superior a $1,5 \mathrm{~cm}$. Pacientes com altura inferior deverão ser submetidos inicialmente as técnicas de aumento real do rebordo ósseo e posteriormente ao enxerto de pele.

Segundo STEINHAUSER (12) esta técnica cirúrgica ao estabelecer o aumento do rebordo desdentado proporciona uma perfeita retençāo da prótese total mandibular.

A sulcoplastia com enxerto epidérmico oferece uma solução ao problema da atrofia do rebordo alveolar e garante uma área chapeável de tamanho adequado e não exposta à probabilidade de recidiva.

\section{REFERÊNCIAS BIBLIOGRÁFICAS}

01. ESSER, J.F. Studies in plastic surgery of the face. Ann Surg, 65:297, March, 1917.

02. GILLIES, H.D. Plastic surgery of the face. London, Oxford University Press, 1920. p.8-12.

03. MATHIS, H. Einfache chirurgiche Massnahmen zur sicherung von Halt und Stabilitat der Prothesen in der altagspraxis. Dtsch Zahnaerztl Z, 6:64, June 1951

04. MOSKOWICZ, Veber de Verpflanzung Thierscher Epidermislaeppchen in die Mundhoehle. Arch Klin Chir, 108:216, 1916.

05. OBWEGESER, $H$. Surgical preparation of the maxila for prothesis. J. Oral Surg 22:127, March 1964.

06. PICHLER, H. Zur Behandlung boesartiger Obserkefer geschwelste. Arch Klin Chir, $167: 789,1931$.

07. PICKERILL, H. Intra-oral sking-graftins: The 


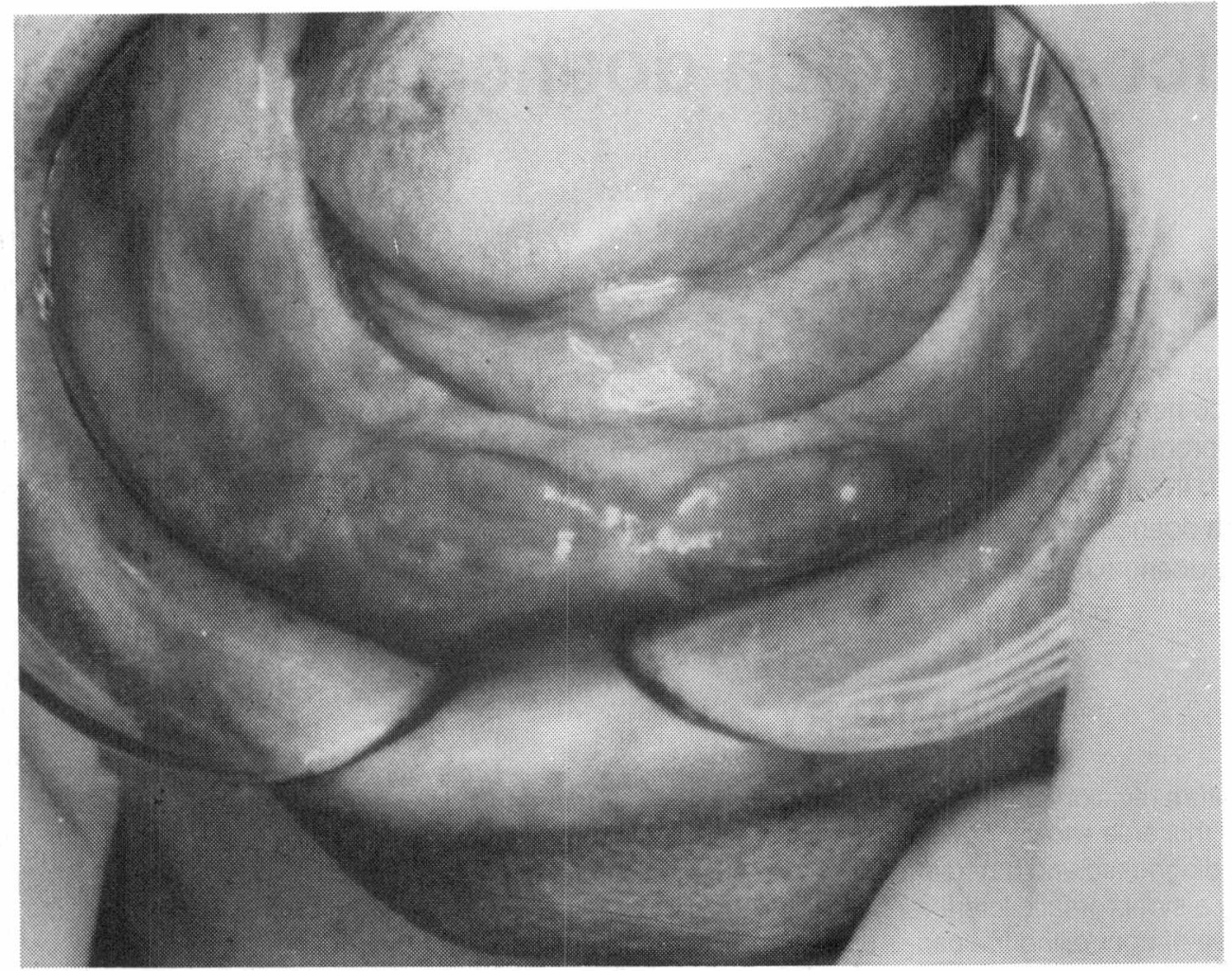

FIGURA A: Aspecto clínico pré-operatório de atresia alveolar de mandíbula. Observa-se por vestibular bilateralmente a linha média lesōes hiperplásicas inflamatórias associadas
FIGURA B: Aspecto pós-operatório 60 dias da sulcoplastia com enxerto epitelial

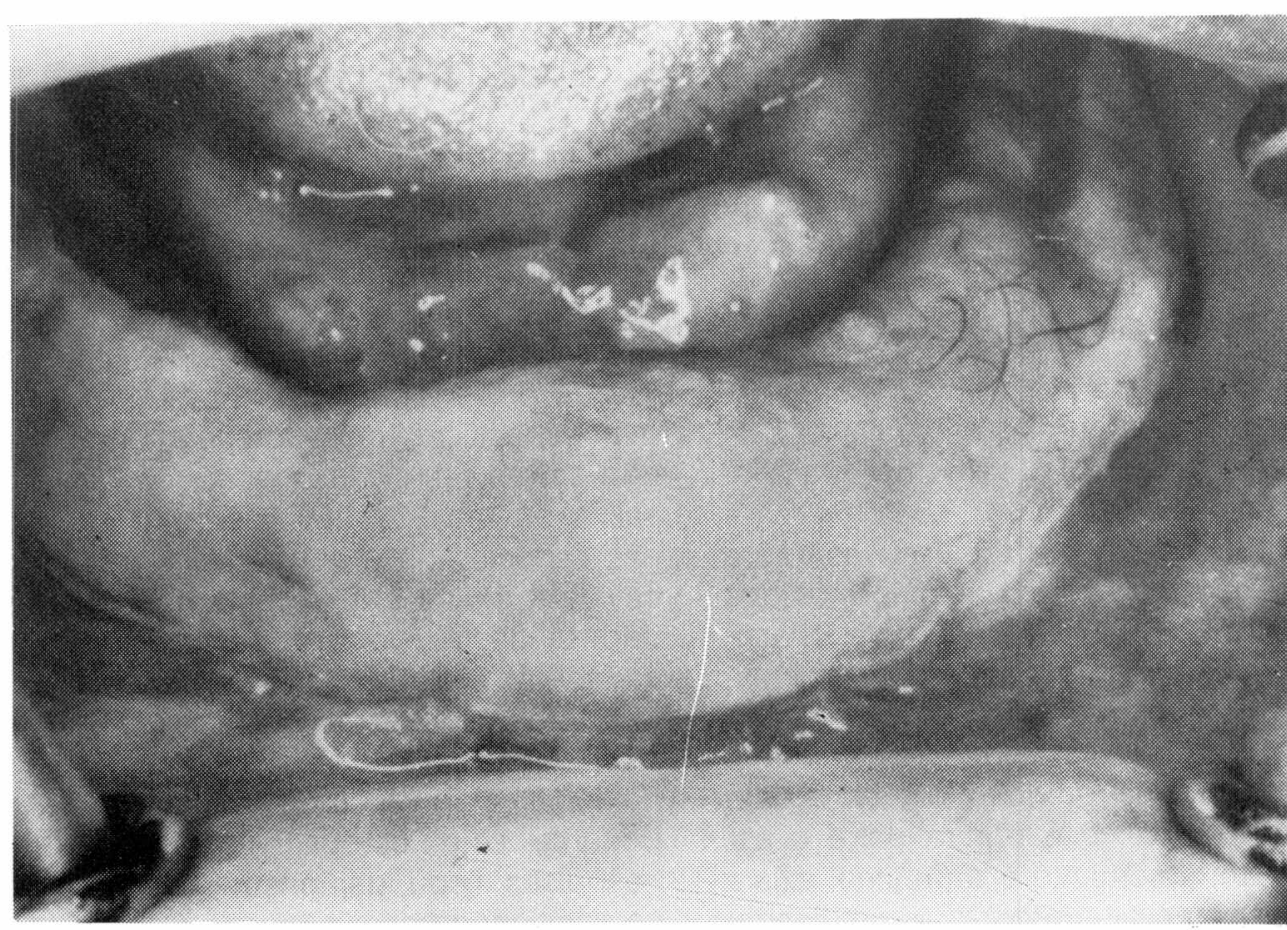

naerztl Z., 7:364 April, 1952.

12. STEINHAUSER, E. J. Oral Surg, 29:(11) 777-85, 1971.

13. TRAUNER, R. Alveoloplasty with ridge extensions on the lingual side of the lower jaw to solve the problem of a lower dental protheis. J. Oral Surg, 5:340, April 1952.

14. WALDRON, C. IN GILLIES (ED.). Plastic surgery of the face. London, Oxford University Press, 1920, p.193-208.
15. WASSMUND, M. Ueber chirurgische Formgestaltung des atrophischen kiefers zum Zwecke prothetischer Versogung Vrtljsschr Zahnn, 47:305, 1931.

16. WEISER, R. Ein Fall von Ankylose, Verlust des Alveolafortsatzes und der Vestibulum oris im Bereich past des ganzen Unterkiefers Oest Ungar Vierte sahrsch Zahnheilk, 34:147, 1918.
11. SCHUCHARDT, K. Die Epidermistransplantation beider Mundvorhofplastic. Zah- 